\title{
Medicinal plants with anti-inflammatory activities from selected countries and regions of Africa
}

This article was published in the following Dove Press journal: Journal of Inflammation Research

\section{Oluwafemi O Oguntibeju}

Phytomedicine and Phytochemistry Group, Oxidative Stress Research Centre, Department of Biomedical Sciences, Faculty of Health and Wellness Sciences, Cape Peninsula University of Technology, Bellville, South Africa
Correspondence: Oluwafemi O Oguntibeju

Phytomedicine and Phytochemistry Group, Oxidative Stress Research Centre, Department of Biomedical Sciences, Faculty of Health and Wellness Sciences, Cape Peninsula University of Technology, Bellville 7535, South Africa Tel +27 21 9538495

Email oguntibejuo@cput.ac.za

\begin{abstract}
Various nonsteroidal anti-inflammatory drugs have been shown to reduce pain and inflammation by blocking the metabolism of arachidonic acid by isoform of cyclooxygenase enzyme, thereby reducing the production of prostaglandin. Sadly, there are many side effects associated with the administration of nonsteroidal anti-inflammatory drugs. However, there are medicinal plants with anti-inflammatory therapeutic effects with low or no side effects. The African continent is richly endowed with diverse medicinal plants with anti-inflammatory activities that have been shown to be effective in the treatment of inflammatory conditions in traditional medicine. Interestingly, scientists have examined some of these African medicinal plants and documented their biological and therapeutic activities. Unfortunately, medicinal plants from different countries in Africa with anti-inflammatory properties have not been documented in a single review paper. It is important to document the ethnobotanical knowledge and applications of anti-inflammatory medicinal plants from selected countries representing different regions of the African continent. This paper therefore documents anti-inflammatory activities of various medicinal plants from different geographical regions of Africa with the aim of presenting the diversity of medicinal plants that are of traditional or therapeutic use in Africa.
\end{abstract}

Keywords: inflammation, inflammatory conditions, local plants, plant potentials

\section{Introduction}

Reports have shown that inflammation is usually triggered by damage to living tissues resulting from bacterial, viral, fungal infections; physical agents; and defective immune response. The fundamental aim of inflammatory response is to localize and eliminate the harmful agents; secondarily, to remove damaged tissue components to culminate in healing of the affected tissues, organs, or system. ${ }^{1-3}$ An inflammatory response involves macrophages, neutrophils known to secrete different mediators that are responsible for the initiation, progression, persistence, regulation, and eventual resolution of the acute state of inflammation. The resolution of inflammation is influenced by several anti-inflammatory mediators and the recruitment of monocytes for the removal of cell or tissue debris. It is possible that the resolution may not occur in the acute phase, thereby turning into a chronic phase. Chronic inflammation plays a role in the burdens associated with pathological conditions in both developed and developing countries, particularly in African countries. For instance, chronic inflammation is known to play a role in the development of obesity-associated diabetes secondary to insulin resistance..$^{3,4}$

Various nonsteroidal anti-inflammatory drugs can reduce pain and inflammation by blocking the metabolism of arachidonic acid by isoform of cyclooxygenase enzyme 
(COX-1 and/or COX-2), thereby reducing the production of prostaglandin. Unfortunately, there are many side effects associated with the administration of nonsteroidal antiinflammatory drugs. However, there are medicinal plants with anti-inflammatory therapeutic effects with low or no side effects. The African continent is richly endowed with diverse medicinal plants with anti-inflammatory activities that have been shown to be effective in the treatment of inflammatory conditions in traditional medicine. Interestingly, scientists have examined some of these African medicinal plants and documented their biological and therapeutic activities. Unfortunately, medicinal plants from different regions in Africa with anti-inflammatory properties have not been documented in a single review paper. Therefore, it is important to document the ethnobotanical knowledge and applications of anti-inflammatory medicinal plants from selected countries representing different regions in the African continent.

For centuries, Africans have treated different disease conditions including inflammatory diseases using medicinal plants. Africa is a vast continent. From Egypt, Morocco, and Algeria in the north to Nigeria and Ghana in the west, Cameroon and Gabon in the center, Kenya and Tanzania in the east, and South Africa, Lesotho, Namibia, Swaziland, and Zimbabwe in the south, there are thousands of plants with therapeutic values. For example, there are over 5000 plant species growing in Zimbabwe with over $10 \%$ of these plants having medicinal value while in South Africa over 30000 flowering plants are available and some of them are used in treatment and management of pain-related inflammatory disorders in both animal and human subjects. ${ }^{5-7}$ The truth is that African traditional medicine is usually the first contact in meeting the primary health care need in Africa and is related to its affordability, accessibility, cultural and spiritual acceptance, and knowledge of its preparations and use. ${ }^{5,8}$ The potentials of plant-derived compounds from African medicinal plants have been reported and the interest to use medicinal plants in treatment and management of disease conditions is growing rapidly in Africa even among educated African urban dwellers.

\section{Medicinal plants with anti- inflammatory activities from countries and regions of Africa \\ Egypt}

In Egypt, plants have been reported to supply natural antiinflammatory agents that may display minimal side effects. Species of the genus Ipomoea and Alstonia have been documented to possess anti-inflammatory activities and scientists have isolated lipoidal and phenolic compounds from this genus. ${ }^{9,10}$

Research report shows that leaf extracts of Ipomoea pescaprae was effective in the treatment of dermatitis caused by jelly fish sting and the edema induced by ethyl phenyl propiolate in experimental animals. ${ }^{11}$ In another experiment, Pongprayoon et $\mathrm{al}^{11}$ isolated compounds from $I$. pescaprae that inhibited prostaglandin synthesis.

In a laboratory-controlled experimental animal model conducted in Egypt, Karawya et al used aerial parts of Ipomoea palmate; Alstonia scholaris; and the leaves of Salix subserrata, S. tetrasperma, and Phyllostachys nigrar (500 $\mathrm{mg} / \mathrm{kg}$ rat body weight of each extract) and anti-inflammatory activities of the plant extracts were subsequently assessed in male and female albino mice. ${ }^{12}$ Different extracts of the aerial parts of $A$. scholaris showed variable anti-inflammatory activity from which the aqueous methanol extract was the most promising, showing significant anti-inflammatory effect 1 hour after carrageenan injection with $64 \%$ inhibition with a maximum inhibition of $91 \%$. The authors also reported that extract of Ipomoea palmata and S. subserrata produced significant anti-inflammatory activity. The authors suggested that the anti-inflammatory activity profile of the aqueous methanol extracts of Alstonia and Ipomoea plant species involve reduction of kinin and prostaglandin $\mathrm{E}_{2}$ while the anti-inflammatory activity of $S$. subserrata may be linked to the reduction of histamine. ${ }^{12}$

\section{Algeria}

Using female rats, Boubekri et al performed anti-inflammatory activity on Genista quadriflora munby extract. ${ }^{13}$ The plants were collected during the flowering season in May 2008 from the area of El Kala in Algeria. The plant is commonly used in Algeria and Morocco in traditional medicine. In the study, anti-inflammatory activity of the plant extract (100 and $200 \mathrm{mg} / \mathrm{kg}$ ) was assessed by carrageenan-induced rat paw while edema was induced by injecting $1 \%$ suspension of carrageenan in $0.09 \%$ sterile physiological saline into the right plantar region of the rat. The n-butanol extract of the $G$. quadriflora demonstrated significant reduction in the edema paw volume in a dose-dependent manner and the aspirin standard $(100 \mathrm{mg} / \mathrm{kg})$ produced a significant inhibitory effect comparable to the group that took the plant extract. Carrageenan paw is an acceptable approach in the determination of anti-inflammatory activity as it involves various mediators. The development of edema induced by carrageenan injection is a three-phase process; the first 90 minutes involves 
the early phase which involves the release of histamine and serotonin, the next phase which commences from 90 to 150 minutes is mediated by kinin, and the last phase (usually after 180 minutes) is mediated by prostaglandin. It was observed that significant inhibitory activity occurred at the third phase (after 3 hours) of edema development. This observation prompted the authors to opine that anti-inflammatory activities of the extract are possibly related to the inhibition of one or more intracellular signaling pathways involved in the effects of inflammatory mediators. Based on the role of free radicals in inflammatory processes, the authors suggested that the anti-inflammatory effect of the extract may be partly linked to its antioxidant content since the extract is very rich in phenolic compounds. ${ }^{14,15}$

\section{Cameroon}

Medicinal plants have been used in traditional medicine in meeting the health needs of people in Cameroon, a country located in central Africa. In Cameroon, research emphasizing discovery of medicinal plants with antioxidant and anti-inflammatory activities is ongoing and recognition has been given to the application of medicinal plants in the treatment and management of several diseases, including inflammatory diseases. In a laboratory scientific study in Cameroon, Sagnia et al examined fresh leaves of Carica papaya, Eremomastax spectiosa, Eleusine indica, Cassia alata, and Polyscias fulva for their anti-inflammatory potentials. ${ }^{16}$ The air-dried and powdered leaf specimen from each plant were macerated separately in ethanol for 48 hours at room temperature and shaking at intervals. Following the extraction procedures, the plant extracts were tested for their anti-inflammatory activities in an experiment. In the assessment of anti-inflammatory activity of the plant extracts, alpha tumor necrosis factor (TNF- $\alpha$ ) production from monocyte was evaluated after culture with different concentration of plant extracts in the presence of lipopolysaccharide (LPS). The authors reported that the plant extracts inhibited the LPS-induced TNF production by monocyte purification in a dose-dependent manner and that the most inhibition was achieved with $1 \mu \mathrm{g}$ of plant extracts by Er. speciosa, P. fulva, and Casia alata followed by El. indica and Carica papaya. It was noted that the antiinflammatory activity of each plant extract is directly related to the concentration of the phenolic compounds and other constituents that were present in the extracts. Other studies have reported that compounds such as alkaloids, saponins, phytosterols, tannins, flavonoids present in medicinal plants possess anti-inflammatory activities. ${ }^{17-21}$
Dichaetanthera africana is a medicinal plant commonly used in Cameroon and Congo to treat various ailments as well as inflammatory diseases. ${ }^{22}$ In investigating the antiinflammatory activity of the plant, Kognou and colleagues collected the stem bark from the Littoral region of Cameroon. ${ }^{22}$ Air-dried and powdered stem bark of the plant was macerated at room temperature in ethanol to obtain a crude extract. For the experiment, the authors used nulliparous and nonpregnant Wistar rats (180-200 g). Anti-inflammatory activity of the extract from the plant was assessed by protein denaturation method as described by Padmanabhan and Jangle. ${ }^{23}$ Diclofenac sodium anti-inflammatory drug was used as standard drug. The reaction mixture consisted of $2 \mathrm{~mL}$ of extract or standard (50-100 $\mu \mathrm{g})$, phosphate buffer saline with pH 6.4 and 5\% egg albumin $(2 \mathrm{~mL})$. This was incubated at $27^{\circ} \mathrm{C}$ for 15 minutes. Denaturation was induced by keeping the reaction mixture at $70{ }^{\circ} \mathrm{C}$ in water bath for 10 minutes. Following cooling, the absorbance was measured at 660 $\mathrm{nm}$ by using double-distilled water blank. Each experiment was done in triplicate. The percentage inhibition of protein denaturation was calculated. Paw edema was induced by injecting intra-peritoneally $0.1 \mathrm{~mL}$ of $1 \% \mathrm{w} / \mathrm{v}$ carrageenan suspension into the sub-plantar region of the hind paw of the rats. Five groups of six rats each were orally treated 1 hour before carrageenan injection with distilled water $(10 \mathrm{~mL} / \mathrm{kg}$ body weight), indomethacin (10 $\mathrm{mg} / \mathrm{kg}$ body weight), and extract (200 mg/kg body weight). The measurement of the paw edema was performed by displacement technique using a vernier caliper to find out the circumference of paw edema immediately before and after 1, 2, 3, 4, and 5 hours, following carrageenan injection. The plant extract inhibited protein denaturation activity at the different concentrations tested. The maximum inflammatory response induced by carrageenan occurred between 1 and 3 hours. All doses of the extract tested were effective in reducing edema throughout the experiment. The authors concluded that ethanolic extract of the plant had appreciable anti-inflammatory activity and thus justifies its use in traditional medicine in the treatment of inflammatory diseases and other disease conditions in Cameroon.

\section{Gabon}

Gabon, like many African countries, has a population that increasingly uses herbal medicine to manage multitude of diseases. In recognition of this, a large program of research on medicinal plants has been carried out at the Institute of Pharmacopoeia and Traditional Medicine in Gabon to contribute effectively to the management of various diseases 
via development of phytomedicines in accordance with government guidelines. The program involves ethnobotanical surveys, experimental laboratory research, and the production of herbal medicines. There are large number of documented plants used for management of diabetes, hypertension, pain, and inflammation. In Gabon, the stem bark of Pseudospondias longifolia and Antrocaryon klaineanum are used in traditional medicine as analgesic and anti-inflammatory agents. ${ }^{24,25}$ To test the phytochemical contents of these antiinflammatory and analgesic agents, Mebale et al collected stem barks of two plants ( $P$. longifolia and A. klaineanum) in the northern part of Gabon. After extraction, phytochemical analysis was performed. ${ }^{25}$ The results showed that the extracts were rich in alkaloids, tannins, saponins, and flavonoids that possibly explain their potential anti-inflammatory and analgesic activities. In an ethnobotanical survey in Gabon, Tchouya et al reported on 52 medicinal plants belonging to 50 genera and 34 families that are traditionally being used in the treatment of HIV/AIDS opportunistic infections. ${ }^{26}$ These plants are also being used as anti-inflammatory agents since inflammation is associated with viral and bacterial infections. The authors observed that 41 of the 52 identified medicinal plants were used in the treatment of 11 disease conditions.

\section{Kenya}

In Kenya, traditional medicine is, broadly, culturally accepted and practiced in various regions where over 400 plant species have been documented to be in use as therapeutic agents and in traditional remedies by traditional healers and by the general public in the treatment and management of many diseases, including inflammatory diseases. ${ }^{27,28}$ Bacterial infections and inflammatory diseases are some of the conditions treated with preparations from medicinal plants in Kenya. ${ }^{29,30}$ It is important to note that many of the inflammatory diseases are associated with synthesis of prostaglandins. In 2003, Matu and van Staden evaluated the anti-inflammatory activities of selected medicinal plants used in traditional medicine in Kenya. ${ }^{27}$ The authors collected plant materials from natural habitat in central and eastern provinces of Kenya and the identities of these plants were confirmed by a botanist at the East African Herbarium, Nairobi, Kenya. Aqueous, methanol, and hexane extracts of the following plants were used: Ajuga remota, Conyza schimperiana, Croton macrostachyus, $C$. megalocarpus, Oxygonum sinuatum, Plectranthus barbatus. Anti-inflammatory activity of each plant extract was assessed by using COX assay. ${ }^{31}$ The results showed that the highest inhibition was with organic extracts of Galinsoga parviflora, Maytenus senegalensis, Mondia whitei, O. sinuatum, P. barbatus, Xzanthoxylum chalybem, and Zanthoxylum usambarense. It was reported that the aqueous extracts showed lower anti-inflammatory activity, and it was concluded that the results confirmed the therapeutic potency of the 12 medicinal plant species assessed in the study and provide justification for their applications in traditional medicine in the treatment of inflammatory diseases and other diseases in Kenya.

\section{Tanzania}

The people of Tanzania have a rich culture of traditional medicine usage and practices with dynamic interethnic cultural interactions of different people from different parts of the country constituting a rich base of herbal and traditional practices. Moshi et al examined the ethnomedicine of the Kagera region in Tanzania and reported on the medicinal plants used in the treatment of various diseases. ${ }^{32}$ It was noted that most of the medicinal plants used had more than one therapeutic usage. For instance, Draceana steudneri was used for treating fibroids and asthma. The prevailing conditions treated with medicinal plants include respiratory tract infections, cardiovascular disease, infectious diseases, and skin diseases and joint pains. It is important to note that all these disease conditions elicit inflammatory responses. The leaves from the plants were the most commonly used parts ( 20 species) followed by the roots ( 13 species) and that monotherapy prepared from the medicinal plants was common compared to mixed preparations from two or more medicinal plants. ${ }^{32}$ Sixteen of the 34 plants used are supported by reports of their usage in literature and there are no reports of their harmful effects in human. The plants whose traditional and therapeutic claims are supported in literature in Tanzania are as follows: Ageratum conyzoides, Bidens pilosa, Boerhavia diffusa, Capparis tomentosa, Casia alata, Clerodendrum myricoides, Lantana camara, Flueggea virosa, and Veronia amybdalina. The above-mentioned plants, which are commonly used in Tanzania, have the possibility of being used in drug development and some of them constitute source of food and nutrition for the local community.

\section{Ghana}

The COX enzymes convert arachidonic acid to prostaglandin. Prostaglandins are strongly linked to the processes involved in inflammation and are responsible for the sensation of pain and redness associated with inflammatory reaction. On the other hand, inhibition of the synthesis of prostaglandin is expected to result in pain relief and reduce inflammation in inflamed tissues. ${ }^{33}$ It is worthy to note that various 
studies have demonstrated that plants possess inhibitory activity against COX enzymes, and it is believed that such plants could play a role in the treatment of pain and inflammatory diseases. ${ }^{33,34}$ To test this, Larsen et al performed anti-inflammatory test on medicinal plants. ${ }^{35}$ They collected plants during the rainy season in Ghana. The plants include the following: Solanum americanum, Veronia colorata, Scoparia dulcis, Hilleria latifolia, Indigofera pulchra, Gardenia ternifolia, and other medicinal plants.

The plants were air dried, turned into powdered form, and extracted using ethanol. The active extracts were identified using high-performance liquid chromatography. The COX-1 assay was carried out based on methods previously described. Seventeen plant species were tested for COX-1 inhibitory activity. The plants displayed inhibitory activities at different concentration. A low inhibition was observed in some of the plants. It was observed that of all the plant extracts that demonstrated inhibition of COX-1, only Gardenia ternifolia is known to have retained its medicinal applications for several decades. Agyare investigated the anti-inflammatory activities of the leaves of Anchomanes difformis and the roots of Colocasia esculenta. ${ }^{36}$ Parts of the two medicinal plants were collected and subsequently identified by a botanist, then processed, and extracted in $70 \%$ methanol. To determine the anti-inflammatory activity of both plants, the investigators used carrageenan-induced foot edema. Carrageenan-induced inflammation of the footpad of chicks was employed to assess the anti-inflammatory property. The chicks were randomly divided into 11 groups with each group consisting of five chicks. The chicks were weighed, and their foot volumes measured using electronic calipers. Chicks in groups 1-3 were administered with 30, 100 , and $300 \mathrm{mg} / \mathrm{kg}$ body weight of $A$. difformis leaf orally. Group 4-6 received 30, 100, and $300 \mathrm{mg} / \mathrm{kg}$ body weight of A. difformis root orally. Groups 7-9 received 30, 100, and $300 \mathrm{mg} / \mathrm{kg}$ body weight of C. esculenta leaf via oral route while groups 10 and 11 received aspirin $(100 \mathrm{mg} / \mathrm{kg})$ and distilled water through oral route. Inflammation or edema was induced by a sub-plantar injection of carrageenan $(0.10 \mu \mathrm{mL}$ of $2 \% \mathrm{w} / \mathrm{v}$ solution) of normal saline into the right footpad of the chicks 1-hour posttreatment. The footpad volumes were measured immediately before the experiment (time zero) and every hour until 6-hour post-carrageenan injection. Results showed that the leaf and root of $A$. difformis and $C$. esculenta elicited anti-inflammatory activities at doses used. The anti-inflammatory experiment shows that the leaf, root of $A$. difformis and leaf of $C$. esculenta possessed significant anti-inflammatory activity with a reduction in edema when compared to control. One limitation of this study, as in some other others, is that the inability of the researchers to isolate the bioactive compounds, thus further study is suggested.

\section{Nigeria}

Over $80 \%$ of Nigerians depend on medicinal plants in treating various acute and chronic diseases. ${ }^{37}$ The use of medicinal plants in Nigeria cut across social and economic classes. Both educated and uneducated people use medicinal plants in Nigeria mainly because of its cultural and spiritual ties. Hassan and colleagues examined the anti-inflammatory activities of five Nigerian plants. ${ }^{37}$ These five medicinal plants are used in traditional medicine in Nigeria. In this study, saponins were extracted from five medicinal plants and tested for their anti-inflammatory activities. Saponins are different groups of natural glycosides that are produced primarily by plants, lower marine animals, and certain bacteria. ${ }^{38}$ The high demand for medicinal plants is associated with their physicochemical properties and biological activities and has led to the emergence of saponins as commercially important compounds that have found usefulness in food, cosmetics, and pharmaceutical industries. ${ }^{39}$ The five Nigerian medicinal plants studied for anti-inflammatory potentials include Schwenkia americana, Asparagus africanus, Dichrostachys cinerea, Ficus iteoph$y$ lla, and Indigofera pulchra. The powdered plant material (100 g each) were extracted with aqueous ethanol (70\%) and further processed to obtain crude saponins extracts. The anti-inflammatory activities of the five plants were tested in Swiss albino and Wistar rats of both sexes. At the end of the experiment, the crude saponin extracts demonstrated significant anti-inflammatory activity in the carrageenan-induced rat paw edema test. Specifically, the result showed that $D$. cinerea $(250 \mathrm{mg} / \mathrm{kg})$ and F. iteophylla $(20 \mathrm{mg} / \mathrm{kg})$ exhibited significant inhibitory activity against the carrageenan edema at all the phases of inflammation and was noticed to be comparable to that produced by ketoprofen $(10 \mathrm{mg} / \mathrm{kg})$. Overall, the results suggest that all the crude saponin extracts tested demonstrated significant anti-inflammatory activity that might be mediated through the inhibition of the release and synthesis of the agents that are involved in inflammation. It has been reported that the biological activities of saponins from medicinal plants are linked to their amphiphilic nature, helping in exhibiting these activities via their capability to intercalate into the plasma membrane culminating in changes in membrane fluidity that in turn affect membrane function, thus bringing about cellular responses. ${ }^{37}$

In another experimental study, Ishola et al examined anti-inflammatory effects of the methanolic root extracts of 
selected Nigerian medicinal plants. ${ }^{40}$ Three plants that are used in the treatment of pain and inflammatory conditions by traditional healers were assessed, which include Alafia barteri, Combretum mucronatum, and Capparis thoningii Schum. Phytochemical screening of the plants shows the presence of alkaloids, saponins, glycosides, cardiac glycosides, and steroidal nucleus. Based on the information provided by traditional healers, fresh roots of the three plants were collected, identified, and processed. The extracts of the plants were dissolved in $0.5 \% \mathrm{v} / \mathrm{v}$ dimethylsulfoxide in physiological saline and were administered to the animals (Sprague-Dawley male rats) by oral gavage. Results from the research report showed that acute oral administration of the three medicinal plants elicited anti-inflammatory effects, and following toxicity test, the extracts from the three plants were considered safe when administered through oral route. It was concluded that the presence of the phytochemicals in the extracts may be associated with the anti-inflammatory potentials of the extracts from the three medicinal plants.

\section{Lesotho}

Lesotho is one of the countries in southern Africa and traditional medicine plays a key role in meeting the health needs of the rural population. To examine the traditional and therapeutic use of selected plants in Lesotho, Shale et al focused on interviewing traditional healers and herbalists from different areas about their role in community health care and on plants used in traditional remedies for the treatment of inflammation. ${ }^{41}$ In the study, 20 traditional healers and herbalists located in different parts of the country were interviewed using questionnaire. The questions asked ranged from the plants used for treating inflammatory and bacterial infections, methods of extraction, extracting solvents, forms and dosage of medications, storage and cultivation of the plants. As part of the study, the authors collected 23 plants used in the treatment of inflammation from two districts in the country (Mohale's Hoek and Qacha's Nek). The authors processed the air-dried leaves and roots from the plants according to previously described methods. The inhibition of prostaglandin synthesis by the plant extracts was assessed using the in vitro COX assay, as described by Jager et al. ${ }^{31}$ The conversion of arachidonic acid to prostaglandins was determined as a measure of the degree of inhibition by the plant extracts. Some of the plants tested include Aster bakeranus, Haplocarpha scaposa, Solanum nigrum, Chenopodium spp, Festuca caprina, Pachycarpus rigidus. Of the 23 plants, 12 were screened for anti-inflammatory and 12 were found to display anti-inflammatory activity above $90 \%$. Hexane and methanol extracts were the most active while aqueous extracts showed lower activity. ${ }^{41}$ This study showed that most of plants used by traditional healers and herbalists in Lesotho are potentially rich source of anti-inflammatory agents.

\section{Swaziland}

Medicinal plants form an essential part of Swaziland's biological resources, and it is important to report that many Swazis depend on traditional medicine for their health care needs. This is because traditional medicine is linked to the culture and religious beliefs of the Swazis. The need to preserve the cultural heritage by documenting information on medicinal plants used in traditional medicine in Swaziland motivated Amusan and colleagues to perform ethnobotanical surveys of medicinal plants in the Kingdom of Swaziland. ${ }^{42}$ Few of the plants used in the region of Manzini, Swaziland include: Spirostachys africana, Trichilia emetic, Ximenia americana, Peltophorum africanum. The investigators reported on traditional medical practitioners in the Mazini region of Swaziland describing 41 remedies for 25 disease conditions including inflammatory disease.

\section{Zimbabwe}

Zimbabwe is very rich in medicinal plants that are used in traditional medicine for treatment of diverse disease conditions. There is a growing interest in traditional medicine in Zimbabwe. Over 5000 plant species are known to be growing in Zimbabwe with possibly over $10 \%$ of them having medicinal potentials that are commonly used in traditional medicine. Traditional medicine remained the most affordable and easily accessible form of treatment in the primary health care system in Zimbabwe. ${ }^{43}$ Maroyi investigated the traditional uses of medicinal plants in south-central Zimbabwe by collating reports on the plant species used in Zimbabwe. ${ }^{5}$ He reported on 93 plant species being used as therapeutic agents in the treatment and management of various disease conditions. Seventy-nine of these 93 plant species are indigenous to Zimbabwe, 14 species are exotic either naturalized as weeds or cultivated in gardens as ornamental or food plants. Some of the plants include Lannea discolour, Seasia tenuinervis, Corisa bispinosa, Flacourtia indica, Ficus ingens, etc.

\section{Namibia}

The traditional healing practices in Namibia have been reported by many researchers. ${ }^{44,45}$ In 1998, Marshall conducted a survey on traditional healers in Windhoek in Namibia. ${ }^{46} \mathrm{He}$ reported that reliance on traditional medicine 
is common both in rural and urban areas emphasizing that people are knowledgeable about identities and applications of medicinal plants in meeting their health care needs. It is reported that there are 2400 traditional practitioners in Namibia and reported that 53 plant species are in demand for medicinal use. The ethnobotanical and indigenous knowledge of Namibian traditional healers play an important role in directing plant genetic resources conservation efforts. ${ }^{47}$ Forty-two plant species found in Kuiseb valley and 53 plant species in Sesfontein have been described as plants used for traditional medicine in topnaar communities while 110 medicinal plants used by communities of San people in the north-eastern part of Otjozondjupa region of Namibia in traditional medicine has been described. ${ }^{48,49}$

Brumbaugh documented 20 plants native to Namibia, located between Angola and South Africa on the Atlantic Coast, that are used for traditional purposes by the local people. ${ }^{50}$ The documentation of the medicinal plants was aimed at preserving the traditional knowledge that is passed orally from generation to generation in Namibia, as is the case in many of the African countries. As indigenous tribes transition from a nomadic, pastoralist lifestyle, this traditional knowledge is at risk of being lost.

As part of documentation of medicinal plants used in Namibia, Zhen et al reported that local herbalists in Namibia use the leaves and roots of Ximenia caffra for various disease conditions. ${ }^{51}$ For instance, extracts from the leaf of $X$. caffra has shown anti-inflammatory activity. To evaluate the effect of $X$. caffra leaf extract on the LPS-stimulated expression of inflammatory enzymes and pro-inflammatory cytokines, the mRNA expressions of inflammatory markers 1L-6, inducible nitric oxide synthase (iNOS), and TNF- $\alpha$ were measured by qPCR. Treatment of cells with leaf extract of $X$. caffra at different concentrations demonstrated dose-dependent response on the expression of $1 \mathrm{~L}-6$, iNOS, and TNF- $\alpha$. The strongest response was seen in $1 \mathrm{~L}-6$. This shows the impact of $X$. caffra leaf extract on the expression of 1L-6, an indication of significant anti-inflammatory activity. ${ }^{51}$ Dan et al documented on 17 medicinal plants that are used by people living on Farm Six in San community in Namibia and that $X$. americana is commonly used in the treatment of bacterial infections and inflammatory conditions. ${ }^{45}$

\section{South Africa}

South Africa is a country with strong history of traditional medicine, and it is interesting to note that the country has more than 30000 flowering plant species. Traditional and therapeutic uses of plants are growing in South Africa.
According to Street et al, it is believed that about 27 million South Africans (about 52\% of the population) depend on traditional medicine mainly from plant sources for their primary health care needs. ${ }^{7}$ This heavy dependence on the part of such a significant proportion of the population is possibly due to relatively easy access to the plants, their affordability, and perhaps the extensive local knowledge and expertise in communities, even in urban areas. Many South Africans consult traditional healers who administer plant preparations to treat various disease conditions including inflammatory diseases. ${ }^{52,53}$ Reports showed that there were about 200,000 traditional healers practicing in South Africa in 1995, compared to 25000 orthodox doctors. ${ }^{54}$ Hypoxis hemerocallidea is one of the medicinal plants that has been used in South Africa to treat diabetes and inflammatory diseases. The plant has recently drawn attention of researchers worldwide because of its beneficial medicinal effects. Geographically, the plant is mostly distributed in the Southern hemisphere and is mostly abundant in southern Africa.$^{55}$ In South Africa, the African potato wildly grows in the Eastern Cape and all the way up to the KwaZulu Natal area. It is also native in the savannah areas of Lesotho, Mozambique, and Zimbabwe. ${ }^{56}$ The therapeutic effects of the African potato were attributed to the presence of sterols, starols, sterolins, norlignan, daucosterols, and hypoxide. ${ }^{57}$ In assessing the anti-inflammatory activity of $H$. hemerocallidea, Ojewole used fresh corms of the plant in animal model. He divided rats into four groups (A to D) of eight rats per group. ${ }^{58}$ Group A rats used as untreated controls were not treated with anything. Rats in group B received distilled water only. Rats in group $\mathrm{C}$ received a graded dose of the aqueous extract of $H$. hemerocallidea. Rats in group $\mathrm{D}$ received diclofenac (100 $\mathrm{mg} / \mathrm{kg}$ body weight). Rat hind paw edema was used as a model of acute inflammation. The rat hind paw edema was induced by intra-plantar injection of fresh albumin $(0.5 \mathrm{~mL} / \mathrm{kg})$. Linear diameter of the injected paw was measured for 3 hours at 30-minute intervals. Administration of the plant extract of $H$. hemerocallidea yielded significant reductions in the acute inflammation of the rat hid paw demonstrating anti-inflammatory activity of the plant.

Aspalathus linearis is an endemic South Africa fynbos species and used to generate herbal tea known as rooibos. Rooibos is used traditionally throughout Africa. In a study conducted by Ajuwon et al, LPS significantly increased the level of hepatic TNF- $\alpha$, IL-1 $\beta$, and IL- $6 .{ }^{59}$ Feeding rooibos (Aspalathus linearis) for 4 weeks prior to the LPS challenge was able to reverse the increase in TNF- $\alpha$ and IL- 6 observed 
in the liver to a level that was comparable to what was seen in untreated control animals. It was suggested that the protective effect shown by rooibos on cytokine formation may be due to the plethora of antioxidant phytochemicals found in rooibos, since previous reports have shown that flavonoids found in rooibos such as luteolin, rutin, and quercetin reduced LPS-induced expression of cytokines.

Several plants have been part of the traditional medical practice of indigenous South Africans for many centuries and one of these plants include Aloe ferox. Currently, Aloe ferox is accepted not only in South Africa or Africa but internationally for its effective antiseptic, cleansing, and anti-inflammatory properties. ${ }^{60}$ In a laboratory-based animal model, Mwale and Masika evaluated the anti-inflammatory effects of Aloe ferox via carrageenan-induced rat paw edema. ${ }^{61}$ Distilled water and indomethacin were administered intraperitoneally to rats in groups 1 (5 mL/kg body weight) and $2(10 \mathrm{mg} / \mathrm{kg}$ body weight), respectively. The extract (50, 100, 200, and 400 $\mathrm{mg} / \mathrm{kg}$ body weight) were administered intraperitoneally to rats in groups 3 to 6 in that order. After 1 hour, the rats were injected with $0.05 \mathrm{~mL}$ of $1 \%$ carrageenan suspension into the foot pads of the left hind paws and measurements were taken according to previously described method. ${ }^{62}$ There was a significant inhibition of the inflammation caused by carrageenan on the paws of rats with the $400 \mathrm{mg} / \mathrm{kg}$ body weight displaying the highest percentage inhibition $(78.2 \%)$. The anti-inflammatory activity of Aloe ferox extract is attributed to its gel containing three malic acid acylated carbohydrates. The plant also contains anti-inflammatory compound aloeresin. It is also noted to contain carboxypeptidase and bradykinase that tend to reduce inflammation and swelling. ${ }^{63}$ Adebayo et al collected fresh leaves of specified plants from Manie van der Schiff Botanical Garden, University of Pretoria, and following previously described methods, they obtained extracts of selected plants and determined the antiinflammatory activity in vitro using the anti-15 LOX model of inhibition. ${ }^{64}$ Crude extracts harvested from two of the plant species tested (Peltophorum africanum and Zanthoxylum capense) showed promising inhibitory activities compared with quercetin as a positive control. Their results suggest that bioactive constituents of $P$. africanum had both antioxidant and anti-inflammatory activities.

\section{Mechanisms of action of plants with anti-inflammatory potentials}

Various mechanisms of actions have been proposed to explain the anti-inflammatory activity of medicinal plants. These include the following:

\section{Inhibition of I5-Lipoxygenases (LOX)}

The lipoxygenase group of enzymes $(5,8,12$, and 15 LOX) plays a role in various inflammatory disorders. The isomeric enzyme 15 -LOX is a key enzyme involved in the synthesis of leukotrienes from arachidonic acids. Biologically active leukotrienes are mediators of many pro-inflammatory and allergic reactions, hence the inhibition of the synthesis of leukotrienes by $15-\mathrm{LOX}$ is seen as one of the therapeutic strategies in the management of inflammatory condition. ${ }^{65}$

\section{Inhibition of NOS}

Inhibition of iNOS is not considered a general characteristic of plant flavonoids. However, plant flavonoids have been reported to inhibit nitric oxide (NO) production, thereby downregulating the expression of iNOS. Flavone and aminosubstituted flavones have also been reported to inhibit NO production. ${ }^{66,67}$

\section{Inhibition of COX}

Flavonoids are a group of polyphenols with the ability to inhibit the biosynthesis of prostaglandins. There are two commonly known isomeric forms of COX (COX-1 and COX-2). The inhibition of COX-1 and COX-2 has been reported as the molecular target of several anti-inflammatory herbal extracts and herb-derived compounds. ${ }^{67}$

\section{Inhibition of phospholipase $A_{2}$}

Arachidonic acid is a precursor of eicosanoids and is released from membrane lipids by phospholipase $\mathrm{A}_{2}$, consequently synthesizing prostaglandins, thromboxanes, and leukotrienes. The inhibition of phospholipase by any therapeutic agent blocks the COX and LOX pathways in the arachidonic cascade have been shown to be effective in the treatment and management of inflammatory conditions. The first flavonoid inhibitor of phospholipase $A_{2}$ to be identified is quercetin, which inhibited human neutrophils. ${ }^{68}$ Selected medicinal plants that have been shown to inhibit phospholipase $\mathrm{A}_{2}$ include Allium sativum, Curcuna longa, A. cepa, Xylopia frutescens. ${ }^{67,69}$

\section{Inhibition of pro-inflammatory cytokines}

Different kinds of pro-inflammatory cytokines are known to regulate inflammatory reactions either directly or by their ability to induce the synthesis of cellular adhesion molecules or other cytokines in certain cell types. Various investigators have reported on the inhibition of pro-inflammatory cytokines following the feeding of rats with plant extracts that are rich in flavonoids. ${ }^{18-21,70}$ 


\section{Modulation of pro-inflammatory gene expression}

The predominant points of cellular regulation affected by herbs and herb-based compounds are the various protein kinases involved in signal transduction including protein kinase $\mathrm{C}$ and mitogen-activated protein kinase. Through inhibition of these enzymes, DNA-binding capacity of transcription factors such as nuclear factor-kappa B or activator protein-1 is regulated, thereby controlling the expression rate of the target gene. ${ }^{71}$

\section{Conclusion}

The aim of this review was to examine scientific studies on anti-inflammatory activities of selected medicinal plants in use in different regions of Africa. In this review, different plants from selected countries in the various geographical region (north, south, east, central, and west African countries) were identified. It can be seen that African countries are repository of medicinal plants that are readily available and used in the treatment and management of various disease conditions, including inflammatory conditions affecting the teaming population. Several drugs are available both in developed and developing countries (Africa inclusive) for treatment and management of inflammatory conditions; however, many of these drugs are associated with adverse effects. Africans who majorly depend on medicinal plants to meet their health needs believe that orthodox drugs are associated with severe side effects, hence many people in Africa, especially those living in poor-resource setting, use medicinal plants in the treatment of inflammation and pain. Many studies have been performed in different African countries to evaluate the anti-inflammatory activities of medicinal plants and to validate their use in traditional medicine. Plants have the capability to synthesize various forms of phytochemical compounds as secondary metabolites, many of which have been identified and continue to be relevant in the treatment of disease conditions in the African setting.

Inflammation remains a complex process that is important for the defense of the host. Excessive production of inflammatory mediators may lead to chronic disease. From this review, it is understood that plant extracts can demonstrate anti-inflammatory activities affecting different stages of the process involved in inflammation, inhibiting formation of cytokines and eicosanoids; prevention of inflammatory reaction cascade from commencing reduce flare, itching, and excessive exfoliation. Research on plants with inflammatory activities is one of the developing areas in modern bio- medicine. Further research on plants with anti-inflammatory activities is needed since a great percentage of traditional healers across Africa may have important information of plants that have not been researched.

\section{Acknowledgement}

The author would like to thank Cape Peninsula University of Technology (CPUT-RJ23) and National Research Foundation (NRF-CPUT RO22) for financial support for the work.

\section{Disclosure}

The author reports no conflicts of interest in this work.

\section{References}

1. Barnes PJ. Targeting the epigenome in the treatment of asthma and chronic obstructive pulmonary disease. Proc Am Thorac Soc. 2009;6(8):693-696.

2. Garrett WS, Gordon JI, Glimber LH. Homeostasis and inflammation in the intestine. Cell. 2010;140(6):859-870.

3. Ahmed AU. An overview of inflammation: mechanism and consequences. Front Biol. 2011;6(4):274-281.

4. Hotamisligil GS. Inflammation and metabolic disorders. Nature. 2005;444(7121):860-867.

5. Maroyi A. Traditional use of medicinal plants in south-central Zimbabwe: review and perspectives. J Ethnobiol Ethnomed. 2013;9:31.

6. Iwalewa EO, McGaw LJ, Naidoo, Eloff JN. Inflammation the foundation of diseases and disorders: a review of phytomedicines of South African origin used to treat pain and inflammatory conditions. Afri J Biotech. 2007;6(25):2868-2885.

7. Street RA, Stirk WA, Van Staden J. South African traditional medicinal plant trade - challenges in regulating quality, safety and efficacy. $J$ Ethnopharmacol. 2008;119(3) :705-710.

8. Abdullahi AR. Trends and challenges of traditional medicine in Africa. Afri J Tradit Complement Altern Med. 2011;8(5 Suppl):115-123.

9. Gupta OC, Rizvi SA, Gupta PC. Chemical examination of a phytosterolin from the seeds of Ipomoea fistulosa. Planta Med. 1971;20(2):72-177.

10. Teow CC, Truong VD, McFeeters RF, Thompson RL, Pecota KV, Yencho GC. Antioxidant activities, phenolic and carotene contents of sweet potato geneotypes with varying flesh colours. Food Chem. 2007;103(3):829-838.

11. Pongprayoon U, Baekstrom P, Jacobsson U, Lindstrom M, Bohlin L. Compounds inhibiting prostaglandin synthesis isolated from Ipomoea pescaprae. Planta Med. 1991;57(6):515-518.

12. Karawya MS, Ammar MM, Hifnawy MS, AL-Okbi SY, Mohamed DA, EL-Anssary AA. Phytochemical study and evaluation of the antiinflammatory activity of some medicinal plants growing in Egypt. Med J Islamic World Academy Sci. 2010;18(4):139-150.

13. Boubekri N, Belloum Z, Boukaabache R, et al. In vivo anti-inflammatory and in vitro antioxidant activities of Genista quadriflora Munby extracts. Der Pharmacia Lettre. 2014;6(1):1-7.

14. Rao KS, Chaudhury PK, Pradhan A. Pro-inflammatory genes as biomarkers and therapeutic targets in oral squamous carcinoma. Food Chem Toxicol. 2010;48(2):729-732.

15. Ananthi S, Raghavendran HRB, Sunil AG, Gayathri V, Ramakrishnan G, Yasanthi HR. In vitro antioxidant and in vivo anti-inflammatory potential of crude polysaccharide from Turbinaria ornate (Marine Brown Alga) Food Chem Toxicol. 2010;48(1):187-192.

16. Sagnia B, Fedeli D, Casetti R, Montesano C, Falcioni G, Colizzi V. Antioxidant and anti-inflammatory activities of extracts from Cassia alata, Eleusine indica, Eremomastax speciosa, Carica papaya and Polyscias fulva medicinal plants collected in Cameroon. PLoS One. 2014;9(8):1-10. 
17. Sen A. Acute rheumatic cardiac associated with Schoenlein-Henoch vasculitis. Anadolu Kardivol Derg. 2012;10:465-466.

18. Ayepola OR, NN Chegou, NL Brooks, OO Oguntibeju. Kolaviron, a Garcinia biflavonoid complex ameliorates hyperglycemia-mediated hepatic injury in rats via suppression of inflammatory responses. $B M C$ Complement Altern Med. 2013;13:363-372.

19. Oyenihi OR, Brooks NL, Oguntibeju OO. Effects of kolaviron on hepatic oxidative stress in streptozotocin induced diabetes. BMC Complement Altern Med. 2015;15:236-243.

20. Oguntibeju OO, Meyer S, Aboua YG, Goboza M. Hypoxis hemerrocallidea significantly reduced hyperglycaemia and hyperglycaemic-induced oxidative stress in the liver and kidney tissues of streptozotocin-induced diabetic male Wistar rats. Evid Based Complement Alternat Med. 2016;2016(2):1-10.

21. Omodanisi EI, Aboua GY, Oguntibeju OO. Assessment of the antihyperglycaemic, anti-inflammatory and antioxidant activities of Moringa oleifera in diabetes-induced nephrotoxic male Wistar rats. Molecules. 2017;22:439-445.

22. Kognou ALM, Ngane RAN, Pawar RS, et al. Anti-inflammatory activity and bioavailability profile of ethanolic extract of Dichaetanthera africana. Pharmacologia. 2017;8(1):32-40.

23. Padmanabhan P, Jangle SN. Evaluation of in vitro anti-inflammatory activity of herbal preparation, a combination of four medicinal plants. Int J Applied Basic Med Res. 2012;2:109-116.

24. Nkeh-Chungag B, Temdie JR, Sewani-Rusikel JR, Fodjo YM, Mbafor JT, Iputo JE. Analgesic, anti-inflammatory and anti-cancer properties of extract of Uapaca guineensis. J Med Plants Res. 2009;3(9):635-640.

25. Mebale AIA, Dibama HM, Affane AL, et al. Phytochemical analysis of aqueous extracts of two medicinal plants from Gabon: Pseudospondias longifolia and Anthrocaryon klaineanum. J Nat Sci Res. 2013;3(9):175-177.

26. Tchouya GRF, Souza A, Tchouankeu JC, et al. Ethnopharmacological surveys and pharmacological studies of plants used in traditional medicine in the treatment of HIV/AIDS opportunistic diseases in Gabon. $J$ Ethnopharmacol. 2015;162:306-316.

27. Matu EN, Van Staden. Antibacterial and anti-inflammatory activities of some plants used for medicinal purposes in Kenya. J Ethnopharmacol. 2003;87:35-41.

28. Aketch CA. A preliminary survey of the conservation status of some plant species in Kenya. In: Edwards S, Asfaw Z, editors. The Status of Some Plant Resources in Parts of Tropical Africa. Botany 2000: East and Central Africa. NAPRECA Monograph; 1992:57-65.

29. Beentje H. Kenya trees, Shrubs and Lianas. Nairobi: National Museums of Kenya; 1994.

30. Maundu PM, Ngugi GW, Kabuye CHS. Traditional food-plants of Kenya. Nairobi: National Museums of Kenya; 1999.

31. Jager AK, Hutchings A, van Staden J. Screening of Zulu medicinal plants for prostaglandin synthesis inhibitors. J Ethnopharmacol. 1996;52:95-100.

32. Moshi MJ, Otieno DF, Mbabazi P, Weisheit A. Ethnomedicine of the Kadera region, north western Tanzania. Part 2: the medicinal plants used in Katoro ward, Bukoba district. J Ethnobiol Ethnomed. 2010;6:1-5.

33. Jeppesen AS, Soelberg J, Jager AK. Antibacterial and COX-1 inhibitory effect of medicinal plants from the Pamir Mountains, Afghanistan. Plants. 2012;1:74-81.

34. Noreen Y, Ringbom T, Perera P, Dnielson H, Bohlin L. Development of radio-chemical cyclooxygenase 1 and 2 in vitro assay for identification of natural products as inhibitors of prostaglandin biosynthesis. $J$ Nat Prod. 1998;61:2-7.

35. Larsen BHV, Soelberg J, Jager AK. Cox-1 inhibitory effect of medicinal plants of Ghana. South Afr J Bot. 2015;99:129-131.

36. Agyare C, Boakye YD, Apenteng JA, Dapaah SO, Appiah T, Adow A. Antimicrobial and anti-inflammatory properties of Achomanes difformis (BI) Engl and Colocasia esculenta (L) Schott. Biochem Pharmacol. 2016;5(1):1-5.
37. Hassan HS, Sule Mi, Musa AM, Abubakar MS, Hassan AS. Anti-inflammatory activity of crude saponin extracts from five Nigerian medicinal plants. Afr J Tradit Complement Altern Med. 2012;9(2):250-256.

38. Francis G, Kerem Z, Makkar HPS, Becker K. The biological action from Asparagus africanus. Phytochemistry. 2002;51(8):1069-1075.

39. Guclu-Ustundag O, Mazza G. Saponins: properties, applications and processing. Crit Rev Food Sci Nutr. 2007;57(3):231-258.

40. Ishola IO, Agbaje EO, Adeyemi OO, Shukla R. Analgesic and antiinflammatory effects of the methanol root extracts of some selected Nigerian medicinal plants. Pharm Biol. 2014;52(9):1208-1216.

41. Shale TL, Stirk WA, Van Staden J. Screening of medicinal plants used in Lesotho for antibacterial and anti-inflammatory activity. $J$ Ethnopharmacol. 1999;67:347-354.

42. Amusan OOG, Dlamini PS, Msonthi JD, Makhubu LP. Some herbal remedies from Manzini region of Swaziland. J Ethnopharmacol. 2002;79:109-112.

43. Gelfand M, Drummond RB, Mavi S, Ademera B. The Traditional Medical Practitioner in Zimbabwe: His Principles of Practice and Pharmacopoeia. Harare: Mambo Press; 1985.

44. Shapi M, Matengu K, Mu H. Indigenous Knowledge System Pilot Study-Oshikoto Region. Namibia: Multidisciplinary Research Centre, University of Namibia; 2009.

45. Dan V, Mchombu K, Mosimane A. Indigenous medicinal knowledge of the San people: the case of farm Six, Northern Namibia. Inform Develop. 2010;26:129-140.

46. Marshall NT. Searching for a cure: conservation of medicinal wildlife resources in Eastern and Southern Africa. Cambridge: TRAFFIC East/ Southern Africa \& TRAFFIC International; 1998.

47. Cunningham AB. Review of ethnobotanical literature from Eastern and Southern Africa. Bull Afr Ethnobotanical Network. 1997;1:23-87.

48. Eynden V, Vernemmen P, Van Damme. The Ethnobotany of the Topnaar. Belgium: Ghent University; 1992.

49. Leger S. The Hidden Gifts of Nature: A Description of Today's Use of Plants in West Bushmanland (Namibia). Namibia: German Development Service and Ministry of Environment and Tourism, Directorate of Forestry; 1997.

50. Brumbaugh MA. Medicinal Plants of Namibia [honors thesis]. Windhoek, Namibia: University of Namibia; 2015.

51. Zhen J, Guo Y, Villani T, et al. Phytochemical analysis and anti-inflammatory activity of the extracts of the African medicinal plant Ximenia caffra. J Anal Methods Chem. 2015;2015:948262.

52. Morris K (2002). South Africa tests traditional medicines. Lancet Infect Dis. 2002;2(6):319.

53. Semenya S, Potgieter M, Erasmus L. Ethnobotanical survey of medicinal plants by Bapedi healers to treat diabetes mellitus in the Limpopo Province, South Africa. J Ethnopharmacol. 2012;141(1):440-445.

54. Settswe C. The role of traditional healers and primary health care in South Africa. Health SA Gesondheid. 1999;4:56-60.

55. Owira PMO, Ojewole JAO. 'African potato' (Hypoxis hemerocallidea corm): a plant-medicine for modern and 21 st century diseases of mankind?-A review. Phytother Res. 2009;23(2):147-152.

56. Afolayan AJ, Sunmonu TO. Studies of in vivo antidiabetic plants used in South African herbal medicine. J Clin Biochem Nutr. 2010;42(2):98-106.

57. Nair VDP, Dairam A, Agbonon A, Arnason JT, Foster BC, Kanfer I. Investigation of the antioxidant activity of African potato (Hypoxis hemerocallidea). J Agric Food Chem. 2007;55(5):1707-1711.

58. Ojewole JAO. Antinociceptive, anti-inflammatory and antidiabetic properties of Hypoxis hemerocallidea Fisch and C.A Mey (Hypoxidaceae) corm (African Potato) aqueous extract in mice and rats. $J$ Ethnopharmacol. 2006;103:126-134.

59. Ajuwon OR, Oguntibeju OO, Marnewick JL. Amelioration of lipopolysaccharide hepatic endotoxemia by Aspalathus linearis aqueous extract via inhibition of pro- inflammatory cytokines and oxidative stress. $B M C$ Complement Altern Med. 2014;14:392. 
60. Van Wyk BE. The potential of South African plants in the development of new medicinal products. SAfr J Bot. 2011;77(4):812-829.

61. Mwale M, Masika PJ. Anagelsic and anti-inflammatory activities of Aloe ferox Mill aqueous extract. Afr J Pharm Pharmacol. 2010;4(6):291-297.

62. Adedapo A, Solidiya Mom Maphosa V, Moyo B, Masika PJ, Afolayan AJ. Anti-inflammatory and analgesic activities of the aqueous extract of Cussonia paniculata stem, bark. Rec Nat Prod. 2008;2(2):46-53.

63. Duke JA. The Green Pharmacy. Emmanus PA: Rodale Press; 1997:392-395.

64. Adebayo SA, Dzoyem JP, Shai LJ, Eloff JN. The anti-inflammatory and antioxidant activity of 25 plant species used traditionally to treat pain in Southern African. BMC Complement Altern Med. 2015;15:1-10.

65. Chedea VS, Jisaka M. Inhibition of soybean lipooxygenases-structural and activity models for the lipooxygenase iso-enzymes family: recent trends for enhancing the diversity and quality of soybean products. InTech. 2005;6:100-130.

66. Krol W, Czuba ZP, Threadgill MD, Cunningham BD, Pietse G. Inhibition of nitric oxide $(\mathrm{NO})$ production inmurine macrophages by flavones. Biochem Pharmacol. 1995;50:1031-1035.
67. Nworu HS, Akah PA. Anti-inflammatory medicinal plants and the molecular mechanisms underlying their activities. Afr JTradit Complement Altern Med. 2015;12:52-61.

68. Lee TP, Matteliano ML, Middletone F. Effect of quercetin on human polymorphonuclear leukocyte lysosomal enzyme release and phospholipid metabolism. Life Sci. 1982;31(24): 2765-2774.

69. Ammon HPT, Anazodo MI, Safayhi H, Dhawan BN, Srimal RC. Curcumin: a potent inhibitor of leukotrienes B4 formation in rat peritoneal polymorphonuclear neutrophils (PMNL). Planta Med. 1992; $58(2): 226$.

70. Ayeleso AO, NL Brooks, OO Oguntibeju (2014). Modulation of antioxidant status in streptozotocin induced-hyperglycaemia male Wistar rats following intake of red palm oil and/or rooibos. Asian Pac J Trop Med. 2014;7(7):536-544.

71. Kim HP, Son KH, Chang HW, Kang SS. Anti-inflammatory plant flavonoids and cellular action mechanisms. J Pharmacol Sci. 2004;96(3):229-245.
Journal of Inflammation Research

\section{Publish your work in this journal}

The Journal of Inflammation Research is an international, peer-reviewed open access journal that welcomes laboratory and clinical findings on the molecular basis, cell biology and pharmacology of inflammation including original research, reviews, symposium reports, hypothesis formation and commentaries on: acute/chronic inflammation; mediators of

\section{Dovepress}

inflammation; cellular processes; molecular mechanisms; pharmacology and novel anti-inflammatory drugs; clinical conditions involving inflammation. The manuscript management system is completely online and includes a very quick and fair peer-review system. Visit http://www.dove press.com/testimonials.php to read real quotes from published authors.

Submit your manuscript here: https://www.dovepress.com/journal-of-inflammation-research-journal 